\title{
Suppressor of fused (Sufu) promotes epithelial-mesenchymal transition (EMT) in cervical squamous cell carcinoma
}

\author{
Ziyu Zhang ${ }^{1, *}$, Yang Zou ${ }^{1, *}$, Meirong Liang ${ }^{1}$, Yuanting Chen ${ }^{1,2}$, Yong Luo ${ }^{1}$, Bicheng \\ Yang1, Faying Liư ${ }^{1}$, Yunna Qin ${ }^{3}$, Deming He ${ }^{3}$, Feng Wang ${ }^{1}$ and Ouping Huang ${ }^{1}$ \\ ${ }^{1}$ Key Laboratory of Women's Reproductive Health of Jiangxi, Jiangxi Provincial Maternal and Child Health Hospital, Nanchang, \\ Jiangxi 330006, P.R. China \\ ${ }^{2}$ Graduate School of Nanchang University, Nanchang, Jiangxi 330031, P.R. China \\ ${ }^{3}$ Department of Pathology, Jiangxi Provincial Maternal and Child Health Hospital, Nanchang, Jiangxi 330006, P.R. China \\ *These authors have contributed equally to this work
}

Correspondence to: Feng Wang, email: jxwangfeng@126.com

Ouping Huang, email: jxhop59@126.com

Keywords: cervical carcinoma; Sufu; 14-3-3५; EMT; FoxMl

Received: January 23, $2017 \quad$ Accepted: November 13, $2017 \quad$ Published: December 11, 2017

Copyright: Zhang et al. This is an open-access article distributed under the terms of the Creative Commons Attribution License 3.0 (CC BY 3.0), which permits unrestricted use, distribution, and reproduction in any medium, provided the original author and source are credited.

\section{ABSTRACT}

Suppressor of fused is essential for the maximal activation of Sonic Hedgehog signaling in development and tumorigenesis. However, the role of Sufu in cervical carcinoma remains unknown. Here, we report new findings of Sufu in regulating the epithelial-to-mesenchymal transition through the FoxM1 transcriptional modulation by 14-3-3 3 protein in cervical carcinoma. Sufu is overexpressed in cervical squamous cell carcinoma and its level in clinical tumor tissues is positively correlated with 14-3-37. Functionanlly, siSufu remarkably prevents the cancer cell migration and invasion. We further demonstrate that the transcriptional activity of Sufu is increased by FoxM1, of which stability is promoted by 14-3-3ろ. Knockdown FoxM1 decreases the invasion of SiHa cells and reconstitution of Sufu rescues the invasion of these cells.Finally, overexpression of Sufu is significantly associated with differentiation grade, FIGO stage, Depth of stromal invasion and vascular cancer embolus. Our findings highlight a novel role for Sufu in cervical carcinogenesis.

\section{INTRODUCTION}

Hedgehog (Hh) signaling pathway plays a critical role in the development, especially in the developing of neural tube and limb bud [1-5]. Besides, abnormal $\mathrm{Hh}$ signaling activity was found in tumorigenesis, for example, medulloblastoma (MB)and basal cell carcinoma (BCC) [6]. Suppressor of fused (Sufu) has been known as the Hh signaling pathway inhibitor, which is considered as a tumor suppressor in early studies [7-9]. However, a surprising observation was made that Sufu was required for maximal activation of Hh signaling [10, 11]. Recently, more and more evidence has shown that aberrant activation of Hh signaling pathway is involved in the formation of respiratory system malignance, gastrointestinal tumor and reproductive system cancers [12-14]. In gynecologic carcinoma, the pathogenesis of cervical cancer is effected by the alterations of $\mathrm{Hh}$ pathway regulators [15-17], but the molecular mechanism remains unclear.

14-3-3 protein family is one of the widely expressed conserved regulatory proteins in eukaryotic cells, which consists of seven family members $(\beta, \varepsilon, \gamma, \zeta, \sigma, \tau$, and $\delta$ ). One of the most striking features of these proteins is the ability to interact with many functional signaling proteins, including kinases, phosphatases and transmembrane receptor proteins [18-20]. In some cases, 14-3-3 proteins bind to other signal molecules via phosphorylationdependent manner by its canonical sequence motifs [RSxpSxP and RxxxpSxP] and non-canonical recognition 
sequences [21]. 14-3-3 proteins promoted tumorigenesis by affecting cell proliferation, apoptosis and epithelial-tomesenchymal transition(EMT) because of mediating the biological function of its binding partners [22].

Here, we present evidence that $14-3-3 \zeta$ is associated with FoxM1, a forkhead transcription factor and is required for FoxM1 stability. We identify that FoxM1 activates Sufu expression by binding to Sufu promoter. Functionally, Sufu knockdown prevents cervical cancer cell EMT in vitro. These data suggest that 14-3-3 $\zeta$ induces EMT in Cervical squamous cell carcinoma (CSCC) through FoxM1-Sufu/Hh cascade.

\section{RESULTS}

\section{Knockdown Sufu inhibits invasion and migration of cervical cancer cells in vitro}

To determine whether Sufu plays a positive role in carcinogenesis, we analyzed Sufu gene alteration using data from The Cancer Genomic Atlas (TCGA) database and the cBioPortal online tool (the cBioPortal for Cancer Genomics) [23, 24]. Interestingly, among 53 examined cancer types or subtypes(from a total of 105 studies), the cervical cancer has Sufu gene amplification (Figure 1A). To investigate the function of Sufu during cervical cancer progression, we used cervical squamous cancer line to clarify the role of Sufu in cell proliferation, invasion and migration. Firstly, we compared the effects of Sufu knockdown and control siRNA on the proliferation of $\mathrm{SiHa}$ cells using EdU incorporation experiment. Western blot analysis indicated that Sufu siRNA successfully reduced Sufu protein level in SiHa cell (Figure 1B). However, knockdown of Sufu protein did not alter $\mathrm{SiHa}$ cell proliferation (Figure 1C, 1D). We then performed transwell migration assay and matrigel invasion assay in $\mathrm{SiHa}$ and HCC94 cell. Interestingly, as shown in Figure $1 \mathrm{E}$ and Supplementary Figure 1, Sufu knockdown not only significantly inhibited the cell migration, but also reduced the cell invasion. These results suggest that knockdown of Sufu by siRNA attenuated cervical cancer cell migration and invasion, but not proliferation.

\section{Sufu promoters EMT in SiHa cell but not in HeLa cell}

Based on the above studies, Sufu is considered to be a master regulator of EMT. To this end, we examined the expression levels of EMT markers in SiHa and HeLa. As expected, in $\mathrm{SiHa}$ cell, western blot analysis showed that Sufu knockdown indeed up-regulated the E-cadherin protein level and down-regulated the Vimentin protein level, respectively (Figure 2A). Nevertheless, depletion of Sufu did not change the protein levels of the EMT markers in HeLa cell, which is a cervical adenocarcinoma cell line. Meanwhile, once we transfected Sufu siRNA into
SiHa cells, the mRNA expression of Hedgehog signaling downstream target genes Ptch1 and Gli1 was obviously decreased as well as Vimentin mRNA expression (Figure 2C). On the contrary, mRNA level of E-cadherin was increased by siSufu. However, neither the mRNA levels of EMT markers nor the protein levels of EMT markers were altered by silencing Sufu in HeLa cells (Figure 2A, 2C). Besides, our immunofluorescence (IF) experiment using anti-Vimentin and anti-E-cadherin antibody to detect endogenous Vimentin and E-cadherin showed that both of their protein levels were changed once Sufu knockdown in $\mathrm{SiHa}$ (Figure 2B).

\section{4-3-3 $\zeta$ regulates the EMT markers through mediating FoxM1-Sufu/Hedgehog cascade}

Western blot analysis showed that Sufu was highly expressed in cervical cancer cell lines (SiHa, HCC94, C33A and HeLa), while in normal tissue (NL), Sufu protein was expressed at low level (Figure 3A). To investigate the mechanism of high level of Sufu in cervical

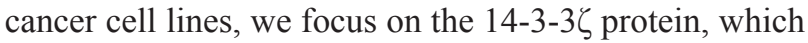
is a binding partner through a phosphorylation-dependent manner. Using the online search tool 14-3-3-Pred (http:// www.compbio.dundee.ac.uk/1433pred) [25], we identified a sequence motif in Sufu (RAPS ${ }^{342} \operatorname{RKDS}^{346}$ ) that closely matches to the 14-3-3 binding consensus $\mathrm{RX}_{1-2} \mathrm{SX}_{2-3} \mathrm{~S}$ [21].Moreover, the S342 and S346 sites were previously reported and required for Sufu stabilization and nuclear accumulation $[10,26]$. Accordingly, we examined the 14-3-3 $\zeta$ protein level in NL and cervical cancer cell lines.

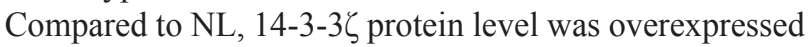
in several cervical cancer cell lines (Figure 3A). Therefore, we speculated that 14-3-3 $\zeta$ induced Sufu expression level. Indeed, 14-3-3 $\zeta$ knockdown abrogated Sufu protein (Figure 3B). However, we failed to detect any binding signal by Co-IP experiment (Supplementary Figure 2). Interestingly, si14-3-3 $\zeta$ down-regulated both the Sufu and Hedgehog target genes mRNA expression levels (Figure $3 E$ ), indicating that $14-3-3 \zeta$ regulated Sufu expression on the transcriptional level. Besides, expression levels of EMT markers were also affected by si14-3-3 $\zeta$ in $\mathrm{SiHa}$ cell (Figure 3C, 3E, 3D) and HCC94 cell (Supplementary Figure 3).

$14-3-3 \zeta$ is a molecular chaperone but not a transcriptional factor, so we speculate that 14-3-3 induces Sufu mRNA level through an intermediator. FoxM1, a transcriptional factor and 14-3-3 $\zeta$ downstream target [27], is associated with cervical cancer progression and pathogenesis [28]. To determine whether FoxM1 is regulated by $14-3-3 \zeta$ in cervical cancer cell line,

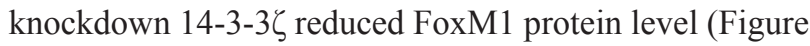
3B, Supplementary Figure 4) rather than mRNA level (Figure 3E). Additionally, data performed by ENCODE project derived from a large collection of ChIP-seq experiments revealed that a putative FoxM1 recognition 
A
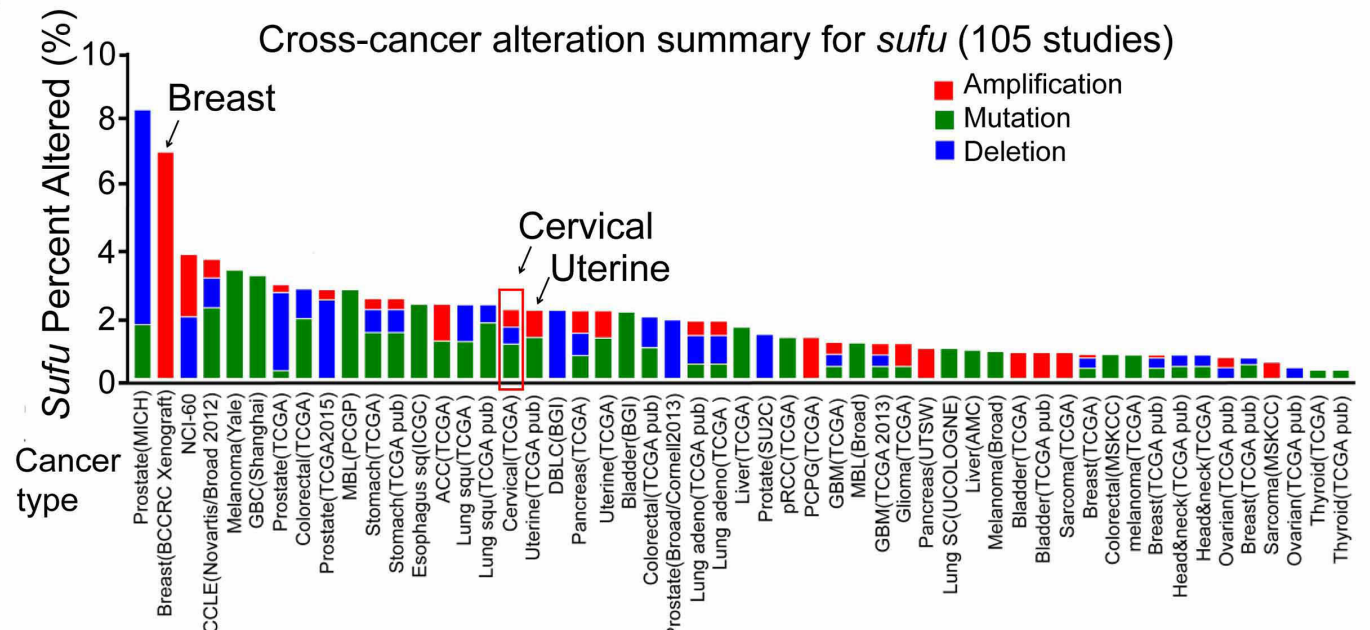

B

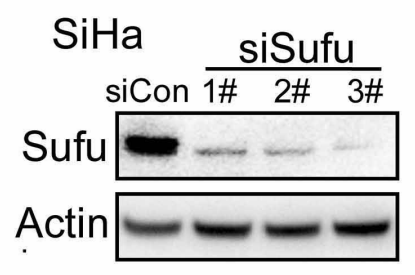

C
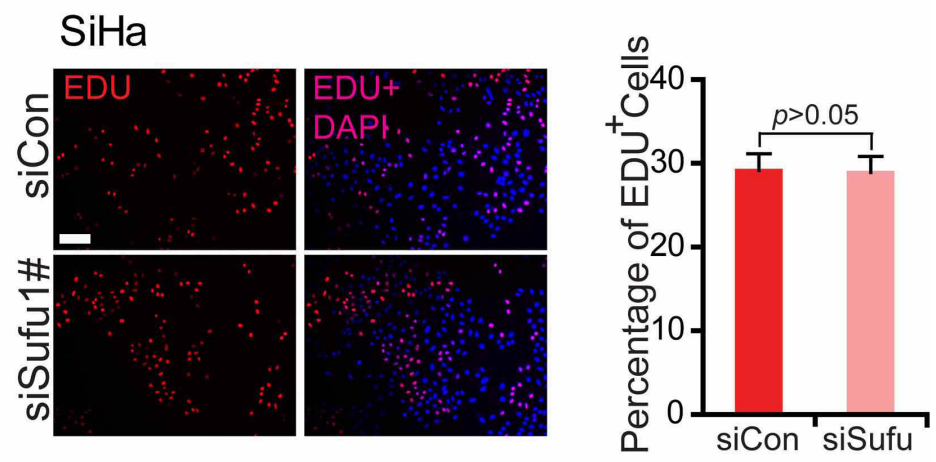

E
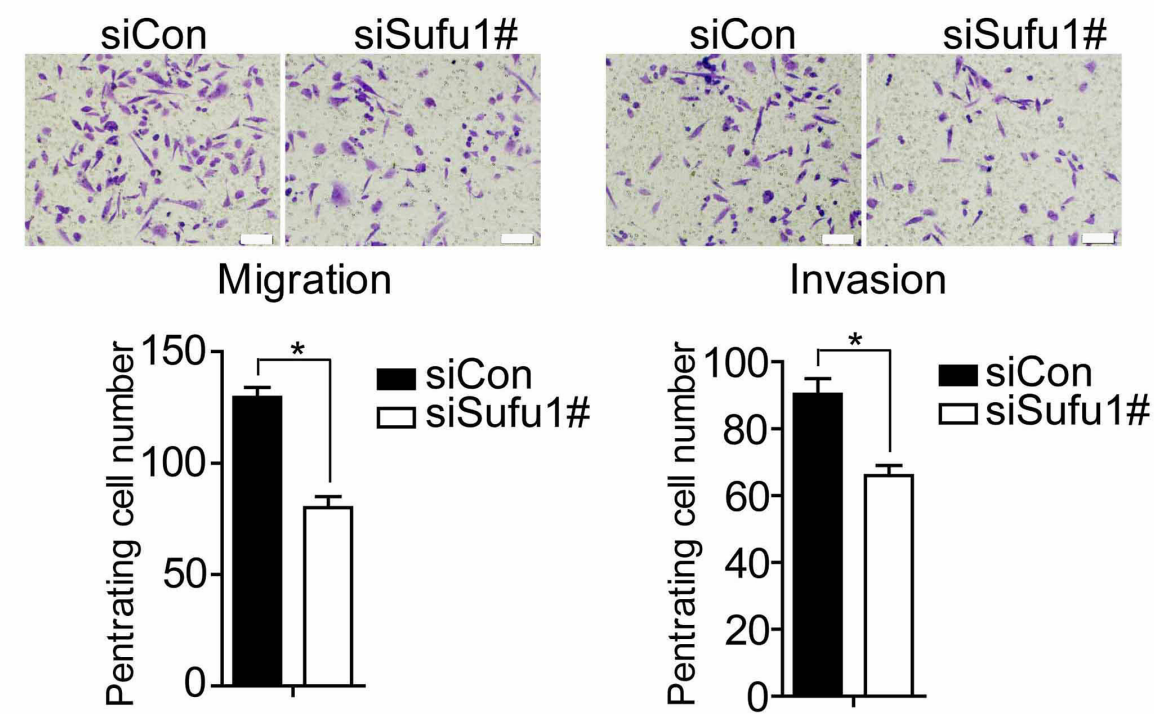

Figure 1: Knockdown Sufu inhibits invasion and migration of cervical cancer cells in vitro. (A) Multidimensional cancer genomics data analysis showing cross-cancer Sufu gene alteration. The histogram showed the frequencies of Sufu gene mutation, deletion, and amplification across cancers. Data were extracted from TCGA database and analyzed using cBioPortal online analyzing tools. (B) Western analysis of SiHa showing the knockdown effect of siSufu. (C) EdU incorporation assays of SiHa cells transiently transfected with control siRNA or siSufu. (D) The percentage of EdU positive cells was blindly calculated with counting nine nonoverlaping fields. Values are means \pm s.d. (E) SiHa cells were transfected with control siRNA or siSufu. After 24 hours of transfection, cells were starved for $24 \mathrm{~h}$ before cell migration and invasion assays were performed with or without matrigel transwell filters. The invaded or migrated cells were stained and counted. Each bar indicates mean \pm s.d. of a representative experiment performed in triplicate. P-values were determined by Student's t-test. " $\mathrm{p}<0.05$. 
sequence (TAAACA/TGTTTA) within Sufu promoter [29], indicating that Sufu is a potential FoxM1 direct downstream target gene (http://genome.ucsc.edu/cgi-bin/ hgGateway). Therefore, we hypothesizes that 14-3-3 regulates Sufu/Hedgehog pathway through mediating FoxM1.

\section{Inhibition of 14-3-3 $\zeta$ decreases migration and invasion of cervical cancer cell}

As the above investigation discovered that 14-3-3 $\zeta$ elevated EMT in cervical cancer cell, we next examined its effect on the cell migration of cervical cancer cell by

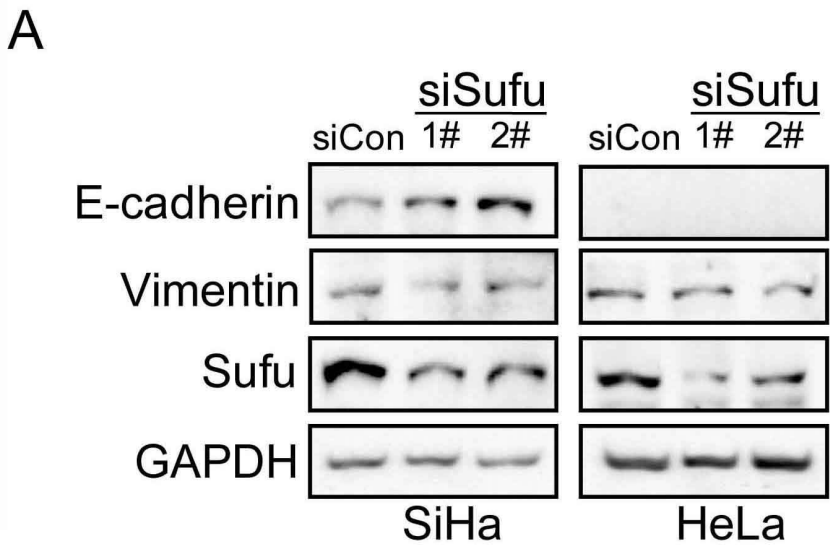

B
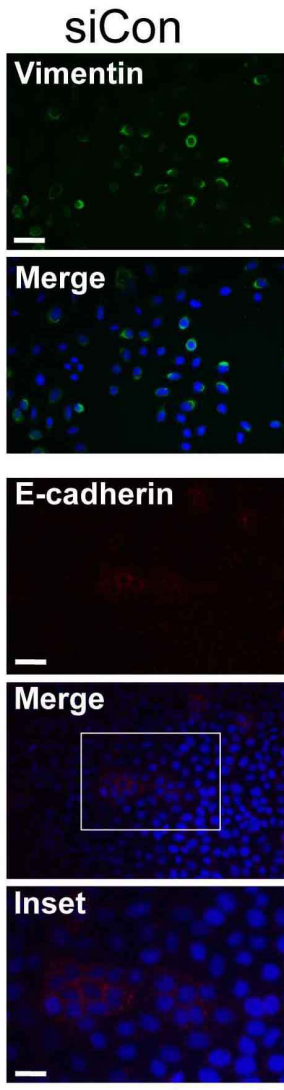

siSufu $1 \#$
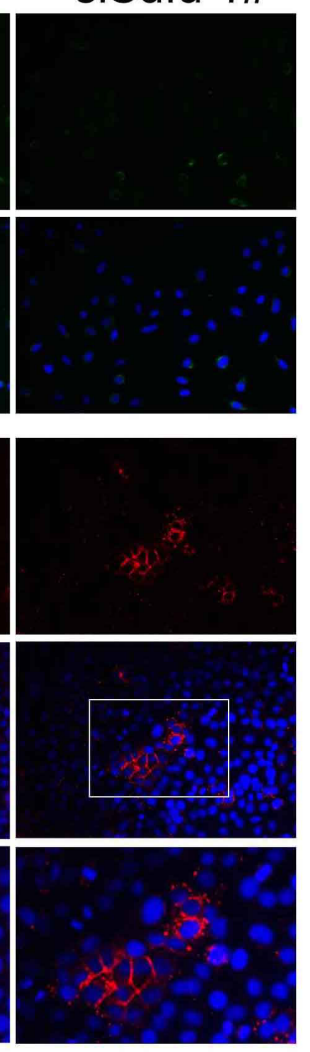

C
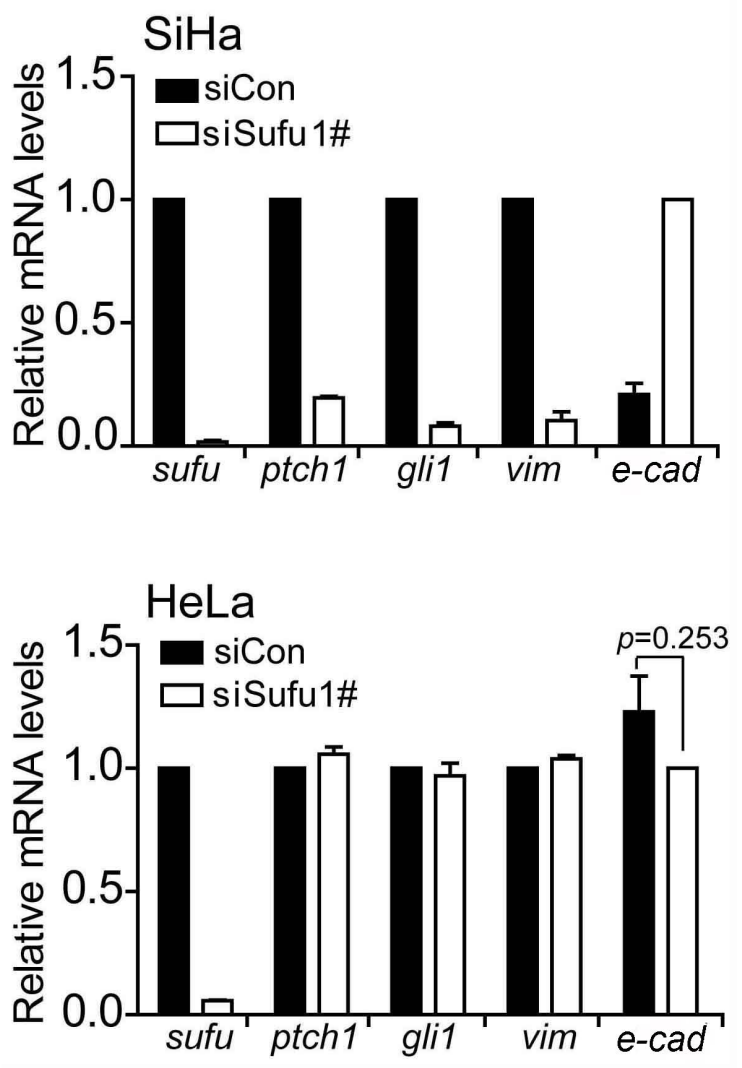

Figure 2: Sufu regulates EMT proteins in SiHa cells but not in HeLa cells. (A) Sufu depletion led to an elevation or a reduction in E-cadherin or Vimentin protein level in SiHa cells but not in HeLa cells, as measured by western blotting. GAPDH was used as the loading control. (B) SiHa cells were transfected with control siRNA or siSufu. Immunofluorescence staining of epithelial (E-cadherin, Red) and mesenchymal (Vimentin, Green) markers was visualized by microscopy. DAPI staining was included to visualize the cell nucleus (Blue). Scale bar $=100 \mu \mathrm{m}$. (C) Sufu was silenced by siRNA in SiHa cells (top) and HeLa cells (bottom), respectively. The EMT markers and Hedgehog pathway target genes were measured by qPCR. Each bar indicates mean \pm s.d. of three independent experiments. 
wound healing assay and transwell migration assay in vitro. Depletion of 14-3-3 $\zeta$ expression in $\mathrm{SiHa}$ and HCC94 caused significant inhibition on motility as compared with empty vector control (Figure 4A, 4B, 4C, Supplementary Figure $5 \mathrm{~A}$ ). We examined the effect of $14-3-3 \zeta$ on the invasion of cervical cancer cell using a matrigel invasion assay. SiHa and HCC94 cell with decreased 14-3-3 $\zeta$ level showed significant inhibition of penetrating cell number (Figure 4D, Supplementary Figure 5B). These data support a role for $14-3-3 \zeta$ in promoting cervical cancer cell migration and invasion.

B

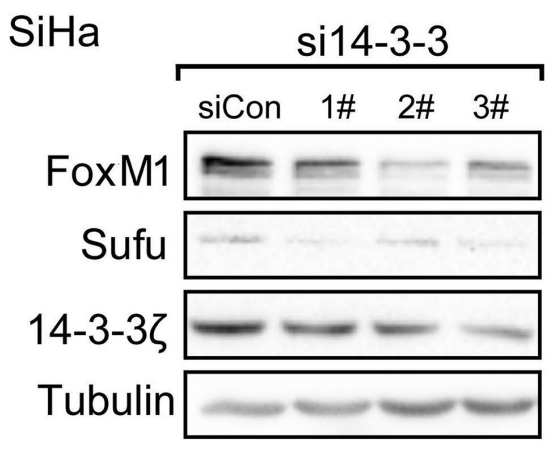

C

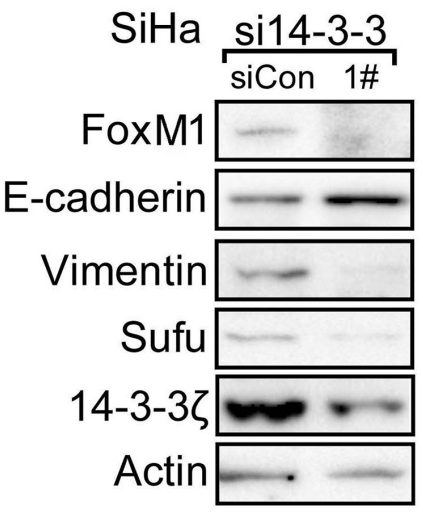

$\mathrm{E}$

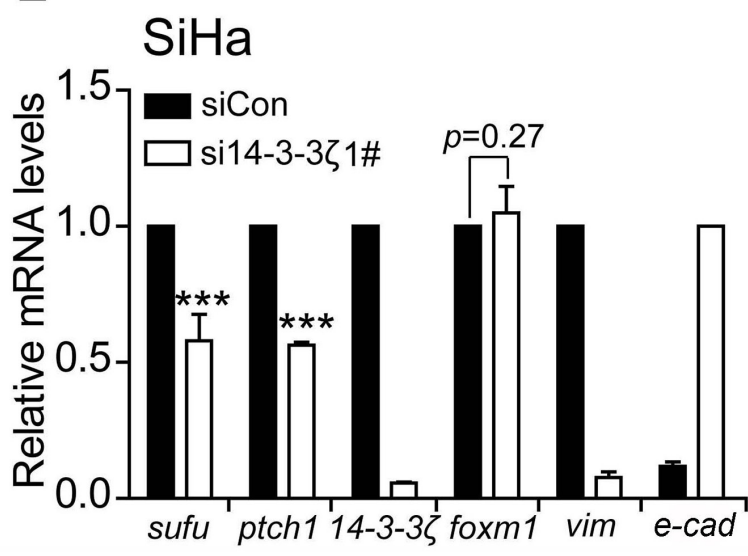

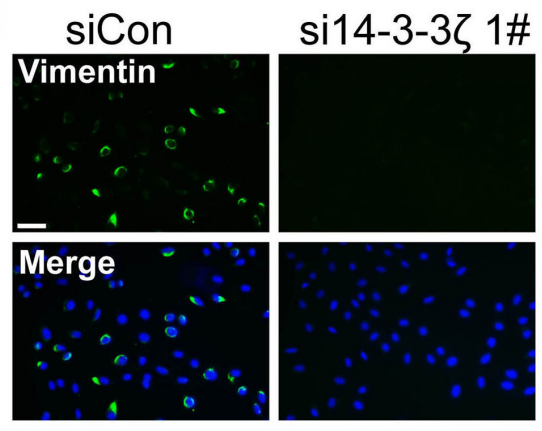
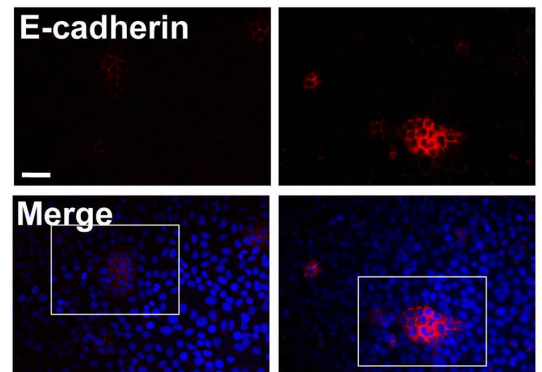

\section{Inset}

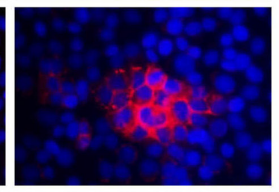

Figure 3: 14-3-3 $\zeta$ regulates the EMT markers through mediating FoxM1-Sufu/Hedgehog cascade. (A) Western blot

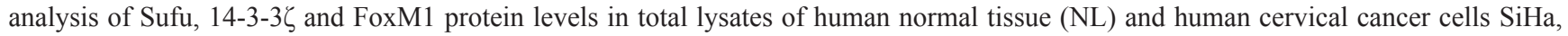
HCC94, C33A and HeLa. GAPDH was used as the loading control. (B) SiHa cells were transfected with control siRNA or si14-3-3

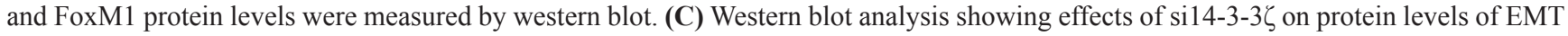

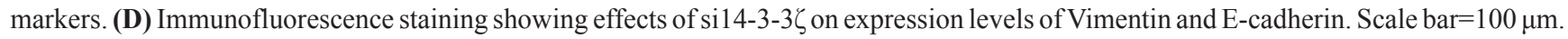
(E) 14-3-3 $\zeta$ was silenced by siRNA in SiHa cells. The EMT markers and Hedgehog pathway target genes were measured by qPCR. Each bar indicates mean \pm s.d. of three independent experiments. ${ }^{* * *} \mathrm{p}<0.001$. 


\section{4-3-3 $\zeta$ is required for FoxM1 stabilization}

Since FoxM1 mRNA level was not altered by 143-3 $\zeta$ knockdown (Figure 3E), but its protein level was decreased (Figure 3C). Additionally, 14-3-3 $\zeta$ enhances protein levels through promoting their stabilization [30]. This interaction between 14-3-3 protein family and their target proteins is mediated by a conserved amphipathic groove, like a dimeric structure, which is thought to be consisted of two 14-3-3 proteins [21]. Again, we found several phosphorylation sites in FoxM1 predicted by 143-3-Pred software. Therefore, we speculated that 14-3-3 $\zeta$ induced FoxM1 protein expression level by promoting FoxM1 stabilization. To that end, we measured the rate of FoxM1 decay after blocking protein synthesis with cycloheximide (CHX). Under the condition of $14-3-3 \zeta-$ depleted, FoxM1 protein level rapidly reduced to half of its original amount at $6 \mathrm{~h}$, but no significant change was

A

B
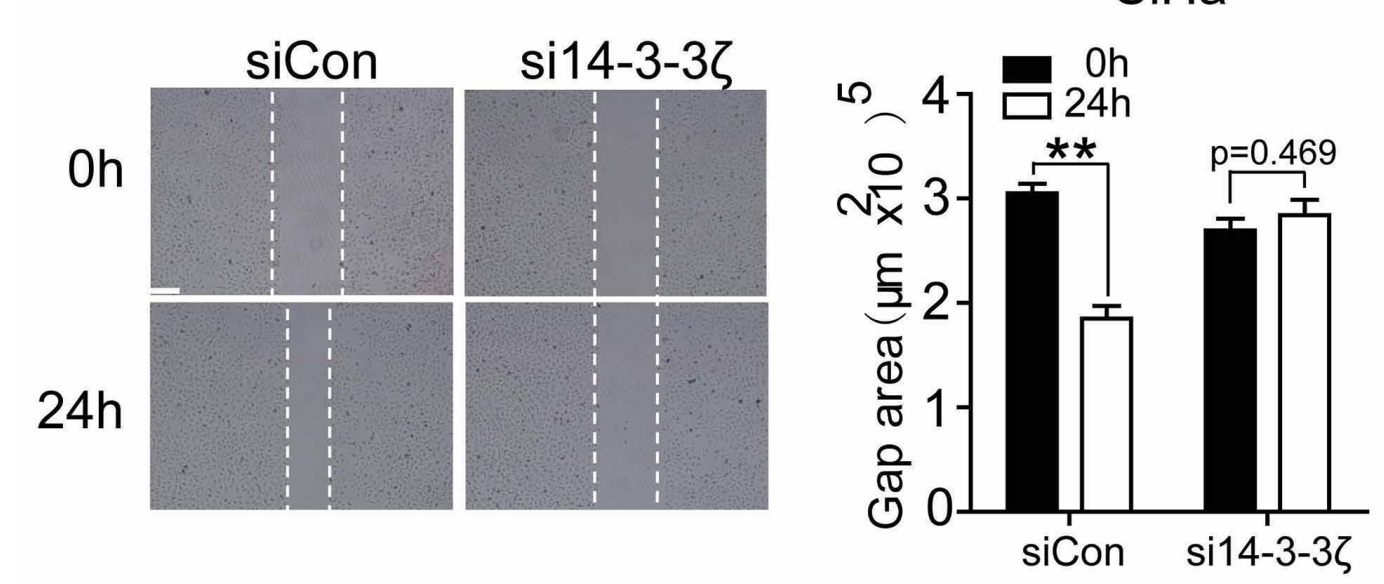

C

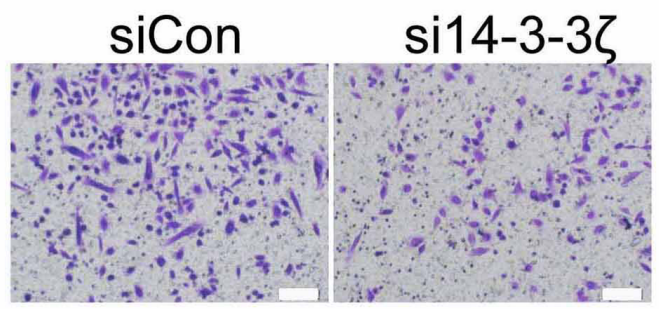

Migration

$\mathrm{D}$

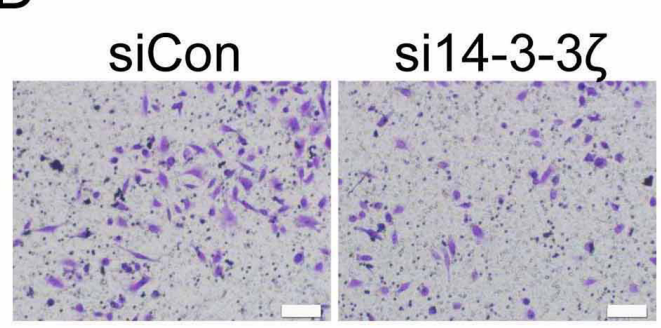

Invasion
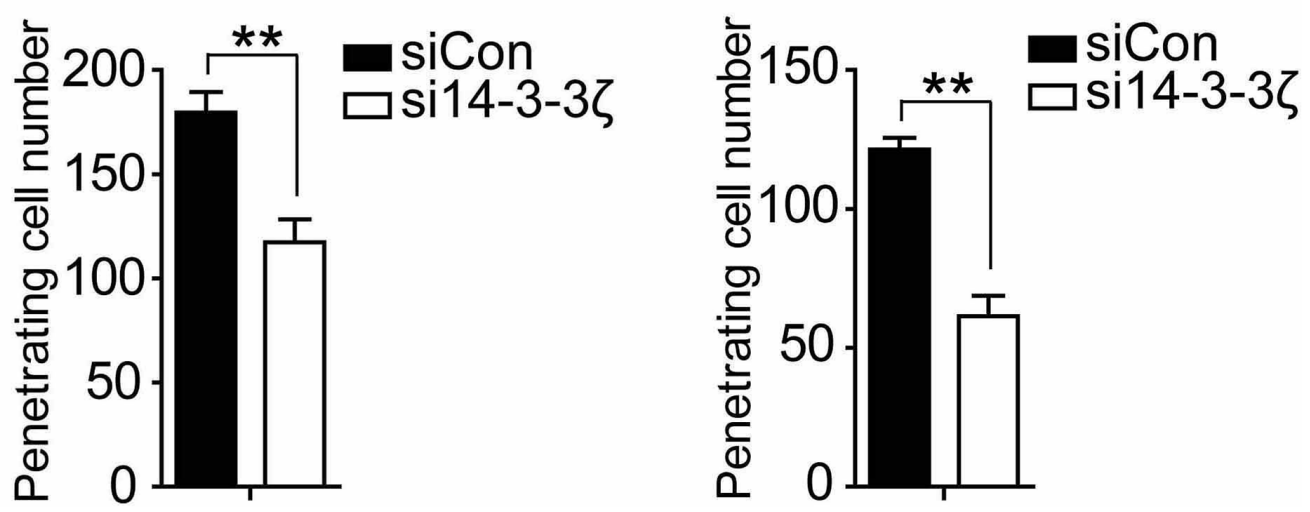

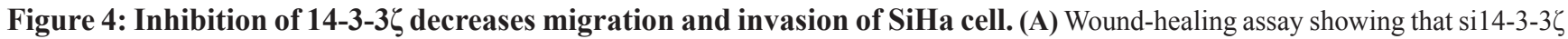
inhibits SiHa cells migration within 24 hours in serum-free medium. Scale bar=200 $\mu \mathrm{m}$. Quantification of (A) was done in and is shown in (B) with counting nine nonoverlaping fields. (C and D) SiHa cells were transfected with control siRNA or si14-3-3 of transfection, cells were starved for $24 \mathrm{~h}$ before cell migration and invasion assays were performed with or without matrigel transwell filters. The invaded or migrated cells were stained and counted. Each bar indicates mean \pm s.d. of a representative experiment performed in triplicate. P-values were determined by Student's t-test. ${ }^{* *} \mathrm{p}<0.01$. 
observed at this time point with control siRNA treatment (Figure 5C, 5D). Furthermore, our co-IP experiment showed that endogenous 14-3-3 $\zeta$ was brought down by FoxM1 (Figure 5A). Remarkably, polyubiquitylation of exogenous FoxM1 was impeded by the presence of exogenous 14-3-3 $\zeta$ (Figure 5B). These results suggested that $14-3-3 \zeta$ is required for FoxM1 stabilization by inhibiting ubiquitin-mediated proteasome degradation.

\section{Sufu is a direct downstream target gene of FoxM1}

To test whether Sufu is a downstream target gene of FoxM1, we used FoxM1 siRNA to analyses the change of Sufu protein level. Consequently, Sufu protein level dramatically decreased after transfected with FoxM1 siRNA (Figure 5E). Simultaneously, the mRNA expression levels of Sufu, Hedgehog target genes and EMT markers were also significantly altered (Figure 5F).
To understand how FoxM1 regulates Sufu expression, we used anti-FoxM1 antibody or normal mouse IgG to immunoprecipitation chromatin in $\mathrm{SiHa}$ cell. Compared to $\mathrm{IgG}$ immunoprecipitates and upstream $5 \mathrm{~kb}$ region of Sufu promoter, a strong amplification band was obtained from anti-FoxM1antibody immunoprecipitates in the FoxM1 binding region (Figure 6A, 6B). Importantly, there was less binding of FoxM1 on Sufu promoter with 14-3-3 depletion (Figure 6A, 6B). Expressing exogenous14-3-3 enhanced the activation of FoxM1-mediated transcription, but there was no effect on the mutant FoxM1 binding site (Figure 6C). In addition, knockdown of FOXM1 expression decreased the invasion of $\mathrm{SiHa}$ cells relative to that of control cells, and reconstitution of Sufu restored the invasion of these cells (Figure 6D, 6E). Taken together, our data indicated that FoxM1 regulated Sufu by binding to Sufu promoter directly and participating in Sufu transcription activity.
A

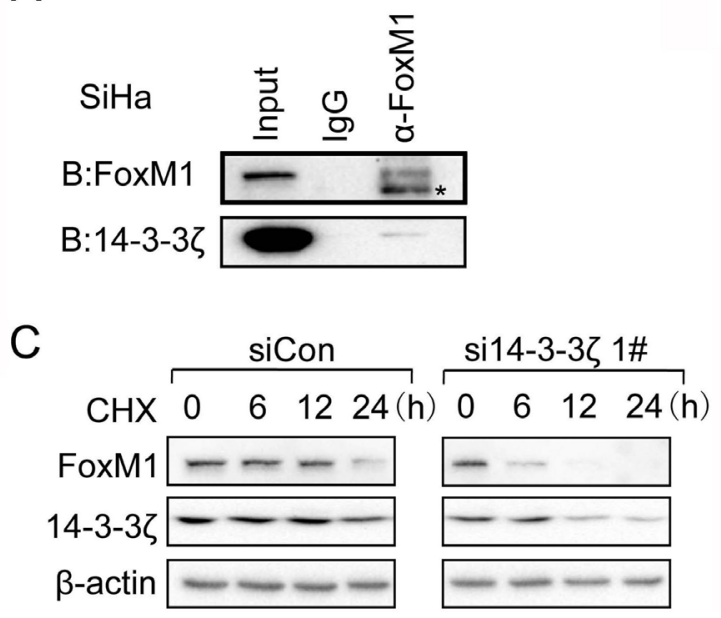

B

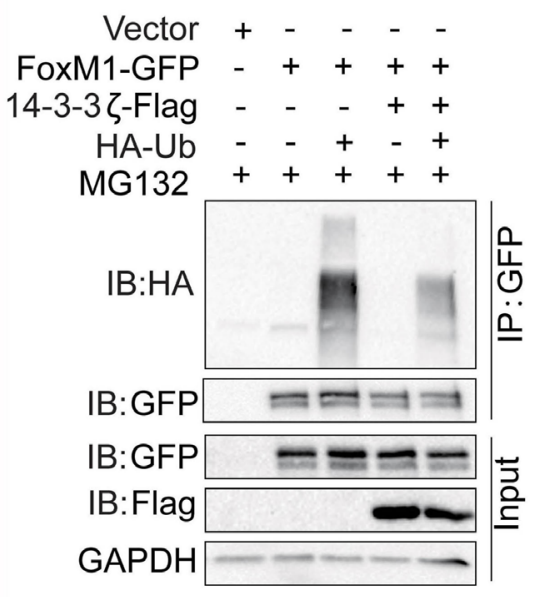

$\mathrm{D}$

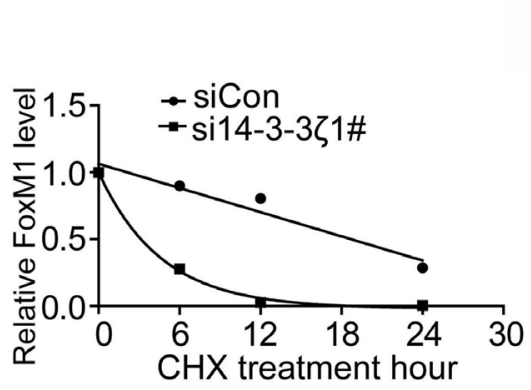

$\mathrm{E}$
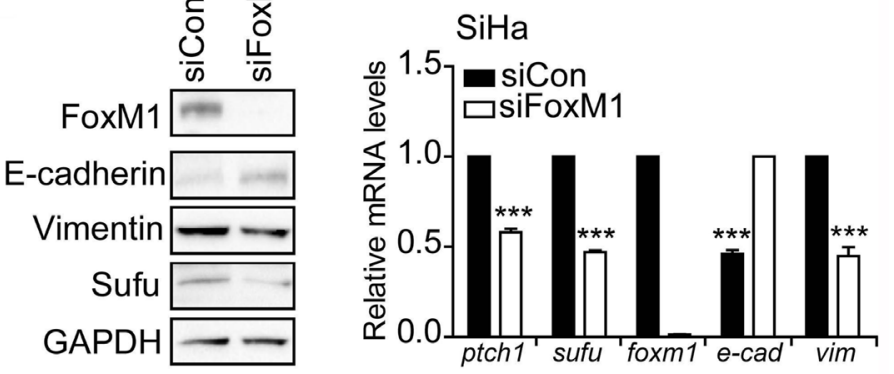

Figure 5: 14-3-3 $\zeta$ regulates Sufu mRNA level through promoting FoxM1 stability. (A) Co-IP experiment showing endogenous

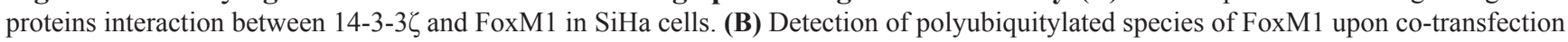

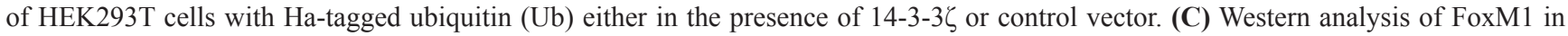

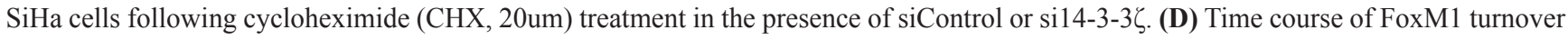
experiments as described in (C). The intensity of FoxM1 bands relative to that of tubulin from each time point was quantified by ImageJ software package and plotted against the incubation time. (E) Western blot analysis showing effects of siFoxM1 on protein levels of Sufu and EMT markers. GAPDH was used as the loading control. (F) FoxM1 was silenced by siRNA in SiHa cells. The EMT markers and Hedgehog pathway target genes were measured by qPCR. Each bar indicates mean \pm s.d. of three independent experiments. ${ }^{* * *}$ p $<0.001$. 


\section{Sufu and $14-3-3 \zeta$ are positively correlated in human tumor tissues}

To investigate the significance of the Sufu regulation by $14-3-3 \zeta$ and FoxM1, we evaluated the levels of Sufu, 14-3-3 $\zeta$ and FoxM1 in human cervical tissue microarray by immunohistochemistry (IHC). Representative IHC staining of Sufu, 14-3-3 $\zeta$ and FoxM1 in CSCC tissue microarray is shown in Figure 7A, 7B and Supplementary Figure 6A. Positive expression of these proteins was found in most CSCC cases: 66 out of the $88(75.0 \%)$ for Sufu, 69 out of 88(78.4\%) for 14-3-3 5 (Figure 7C) and 60 out of the $88(68.2 \%$ ) for FoxM1(Supplementary Figure 7B), and there was a strong correlation between

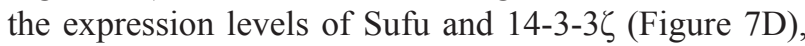
14-3-3 $\zeta$ and FoxM1(Supplementary Figure 6C), Sufu and FoxM1(Supplementary Figure 6D). By contrast, positive expression of both proteins was hardly found in NL cases (Figure 7C, Supplementary Figure 6B). Meanwhile, we also evaluated the expression level of Gli2, a terminal transcription factor in Hedgehog signaling, was overexpressed in CSCC tissue (Supplementary Figure 7). This means that Hh signaling is indeed over activated. Besides, the overexpression of Sufu was correlated with differentiation grade $(p=0.008)$, FIGO stage $(p=0.004)$, depth of stromal invasion $(\mathrm{p}=0.041)$ and vascular cancer embolus $(p=0.046)$, no significant correlation was observed between Sufu and other clinicopathological factors, including age $(\mathrm{p}=0.198)$, lymph node metastasis $(p=0.358)$ (Table 1).

\section{DISCUSSION}

Sufu is involved in the Hh signaling pathway maximal activation [10]. Furthermore, the data from the TCGA database showed that alters of Sufu in cervical cancer have a certain proportion of the amplification (Figure 1A). Accordingly, we speculate that the novel
A

Sufu_promoter

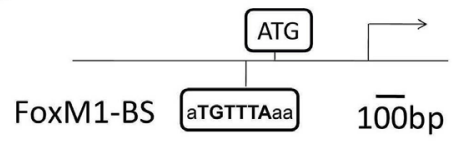

B

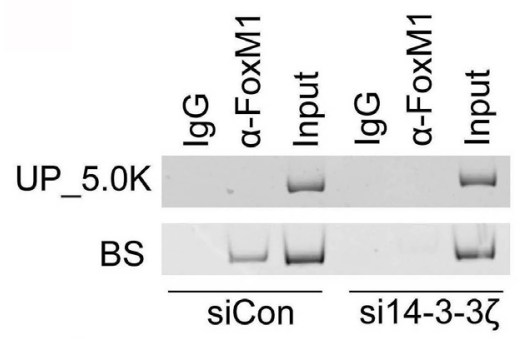

C

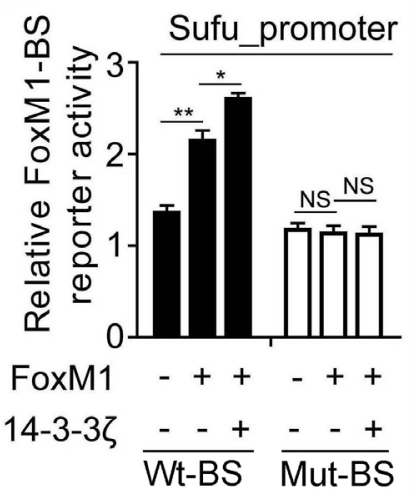

D
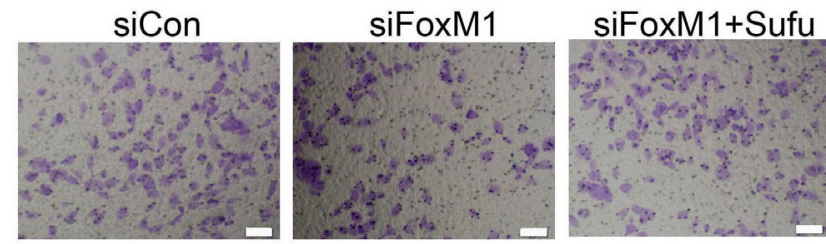

E

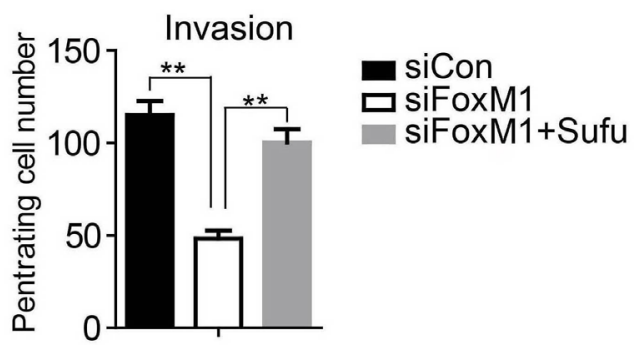

Figure 6: Sufu is a direct downstream target gene of FoxM1. (A) Schematic drawing showing the Sufu promoter region including two FoxM1-binding sites (BS). (B) PCR analysis of FoxM1 ChIP products in the Sufu promoter regions in SiHa cells. (C) Sufu luciferase constructs, as indicated, were transfected into $293 \mathrm{~T}$ cells together with indicated plasmid for $48 \mathrm{~h}$ and subjected to a luciferase reporter assay. The results were normalized to the Renilla luciferase activity and are expressed as the fold change in relative luciferase activity compared with the control. Error bars represent the mean and S.D. of three independent experiments. (D) HCC94 cells were transfected with control siRNA or siFoxM1 or siFoxM1 and Sufu plasmid. After 24 hours of transfection, cells were starved for $24 \mathrm{~h}$ before cell invasion assays were performed with or without matrigel transwell filters. The invaded or migrated cells were stained and counted in (E). Each bar indicates mean \pm s.d. of a representative experiment performed in triplicate. P-values were determined by Student's t-test. ${ }^{*} \mathrm{p}<0.05,{ }^{* *} \mathrm{p}<0.01$. 
Table 1: Relationship between Sufu expression and clinic pathological characteristics in CSCC

\begin{tabular}{|c|c|c|c|}
\hline Variables & $\begin{array}{l}\text { No. of patients } \\
(n=88)\end{array}$ & $\begin{array}{c}\text { Sufu } \\
\text { positive }(\%)\end{array}$ & $p$ value \\
\hline Age & & & 0.198 \\
\hline$<40$ & 30 & $25(83.3 \%)$ & \\
\hline$\geq 40$ & 58 & $41(70.7 \%)$ & \\
\hline Differentiation grade & & & 0.008 \\
\hline 1 & 16 & $8(50.0 \%)$ & \\
\hline 2 & 69 & $55(79.7 \%)$ & \\
\hline 3 & 3 & $3(100.0 \%)$ & \\
\hline FIGO stage & & & 0.004 \\
\hline I & 77 & $59(76.7 \%)$ & \\
\hline II & 11 & $7(69.6 \%)$ & \\
\hline Depth of stromal invasion & & & 0.041 \\
\hline$<1 / 2$ & 37 & $22(59.5 \%)$ & \\
\hline$\geq 1 / 2$ & 51 & $44(86.2 \%)$ & \\
\hline Vascular cancer embolus & & & 0.046 \\
\hline No & 52 & $35(67.3 \%)$ & \\
\hline Yes & 36 & $31(86.1 \%)$ & \\
\hline Lymph node metastasis & & & 0.358 \\
\hline No & 77 & $55(71.4 \%)$ & \\
\hline Yes & 11 & $11(100.0 \%)$ & \\
\hline
\end{tabular}

A

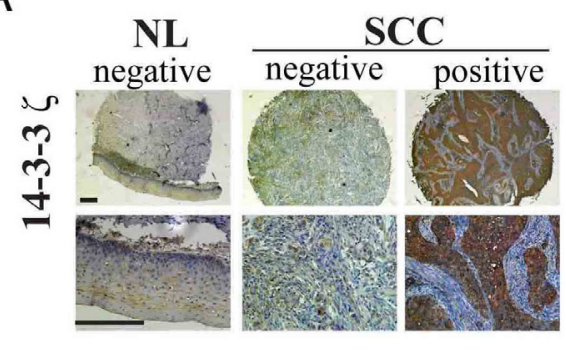

C

\begin{tabular}{|c|c|c|c|}
\hline \multirow{2}{*}{ Biomarkers } & NL & SCC & \multirow{2}{*}{$p$ value } \\
\cline { 2 - 4 } & $n(\%)$ & $n(\%)$ & \\
\hline Sufu & $0 / 13(0)$ & $66 / 88(75.0)$ & $<0.001$ \\
\hline $14-3-3 \zeta$ & $1 / 12(8.3)$ & $69 / 88(78.4)$ & $<0.001$ \\
\hline
\end{tabular}

B

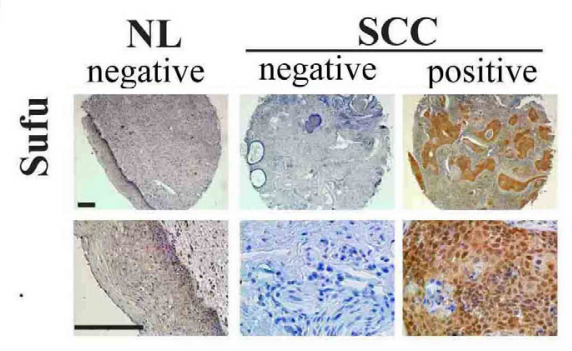

D

\begin{tabular}{|c|c|c|c|c|}
\hline & & \multicolumn{2}{|c|}{ Sufu } & \multirow{2}{*}{ Total } \\
\hline & & Negative & Positive & \\
\hline \multirow{2}{*}{$14-3-3 \zeta$} & Negative & 13 & 6 & 19 \\
\hline & Positive & 9 & 60 & 69 \\
\hline \multicolumn{2}{|c|}{ Total } & 22 & 66 & 88 \\
\hline
\end{tabular}

Figure 7: Sufu and 14-3-3 $\zeta$ are positively correlated in human tumor tissues. (A) A representative image showing the expression

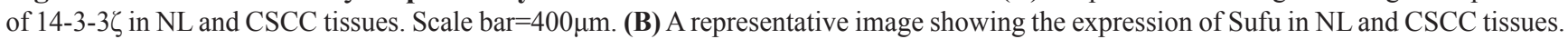

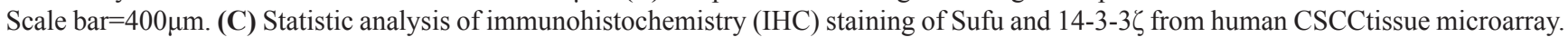

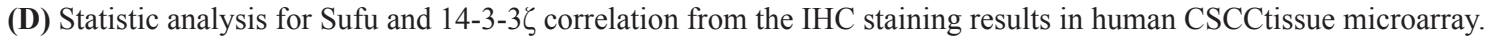


function of Sufu also plays a positive role in the development of cervical cancer. Firstly, we transiently transfected Sufu small interfering RNA into cervical cancer cells (Figure1B) to perform EdU insertion experiments, however, we found no effect of silencing Sufu on cell proliferation (Figure 1C, 1D). Then, we carried out transwell experiments to study the effect of Sufu on migration and invasion in SiHa cells, and Sufu knockdown slowed the motility and invasiveness of cervical squamous cell carcinoma SiHa cells (Figure 1E, 1F). CSCC originates from cervical epithelial cell, which is gradually from epithelial carcinoma in situ invading into stromal, and then metastasize to other parts of the body, the characteristics of which is very similar with EMT [31]. We identified that knockdown of Sufu in SiHa cells downregulated the Vimentin (an interstitial cell marker) and upregulated the E-cadherin (an epithelial cell marker) expression (Figure 2). Additionally, previous studies have reported that Hh pathway is frequently overactivated in cervical cancer $[16,32]$ and we also discovered that Sufu was overexpressed in cervical cancer cell lines (Figure 3A).

However, there are different between squamous cell carcinoma and adenocarcinoma in EMT regulated by Sufu. We also found that Sufu knockdown reduced Hh downstream target genes Gli and Ptch1 (Figure 2C) in cervical squamous cell lines ( $\mathrm{SiHa}$ and HCC94) rather than in adenocarcinoma cell line (HeLa) (Figure 3A, 3D). Wound healing assay revealed that Sufu siRNA did not change the migration of HeLa cell (Supplementary Figure 8). These results suggest that depletion of Sufu decreases Hh signaling pathway activity and only inhibits EMT in cervical squamous cell lines. We consider that the Hh signaling is destructed between Sufu and Gli in HeLa. Maybe mutations are produced in Sufu or Gli, resulting in the interaction between them does not exist. Subsequent work will be performed to investigate the exact mechanism in order to understand the importance of Sufu in distinguishing cervical squamous cell carcinoma and cervical adenocarcinoma cell carcinoma.

Here, we consider the Sufu as a downstream target of $14-3-3 \zeta$ is based on three reasons: 1) $14-3-3 \zeta$ is highly expressed in many tumor types and binds to target proteins by a phosphorylation manner [21]; 2) Sufu contains a conserved 14-3-3 binding motif, of which S342 and S346 sites have also been reported to be phosphorylated [26]; 3) 14-3-3-Pred software predicts the two sites are the candidates of 14-3-3 binding sites. Through the above three points, we suppose that Sufu is a potential target for the 14-3-3. But unfortunately, we fail to find any binding signal between Sufu and $14-3-3 \zeta$ in co-IP experiment (Supplementary Figure 1). We consider this is likely because the wild type Sufu is hardly interacted with 14-3-3 , so we make use of sustained phosphorylated Sufu mutations (S342D, S346D, S342/6D) to carry out Co-IP experiment again, but we are unable to find any combination of signal (data not shown). However, it is very interesting that when we knockdown 14-3-3ร, Sufu mRNA and protein levels are both reduced, indicating that Sufu is a downstream target gene of $14-3-3 \zeta$. Subsequent experiments also demonstrate that Sufu expression is regulated by a 14-3-3 $\zeta$ binding protein: FoxM1. Both of $14-3-3 \zeta$ and FoxM1 regulate Hh signal downstream specific target genes and EMT markers. In our protein turnover assay, we find that FoxM1 stability is required for 14-3-3 $\zeta$ through ubiquitin-proteasome pathway [33, 34]. The above results indicate that 14-3-3 $\zeta$ upregulates Sufu transcriptional level is depend on FoxM1 stabilization, so as to active Hh signaling pathway and ultimately accelerate the progression of cervical cancer EMT.

Finally, we analyze the association between overexpression of Sufu and clinical characteristics in cervical cancer tissue microarray to explore the possibility of clinical diagnosis of Sufu. The expression of Sufu is correlated with differentiation grade, FIGO stage, Depth of stromal invasion, vascular cancer embolus. It is possible for Sufu as a new diagnostic marker and therapeutic target for CSCC.

\section{MATERIALS AND METHODS}

\section{Plasmids, siRNA and CSCC and normal tissues}

The Sufu-GFP plasmid was generous gift

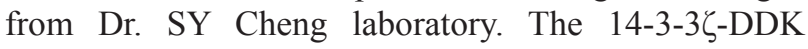
plasmid was purchased from OriGene. siRNA were all purchased from Invitrogen, siSufu1\#:GGCAGCUUGAGAGCGUACAUCUGAA;siSufu2\#:GGAUUUAGAAGAUUUGACUUCUCCA;siSufu-3 \#: CCCUUGGACUAUGUUAGCAUGUACA.siFoxM11\#:CCCUGCCCAACAGGAGUCUAAUCAA;siFoxM12\#:GCCAUGAUACAAUUCGCCAUCAACA;siFoxM13\#:CGCAUGACUUUGAAAGACAUCUAUA.si14-3-3ל1\#: ACAGCACGCUAAUAAUGCAAUUACU;si14-3-3ל2\#: GAGAGACAACUUGACAUUGUGGACA.Si14-3-3 3 3\#: GGAUACCCAAGGAGACG- AAGCUGAA; 88 CSCC and 13 normal cervical tissue specimens used for IHC were obtained from patients without receiving any preoperative chemotherapy or radiotherapy at Jiangxi Provincial Maternal and Child Health Hospital from January 2008 to January 2013. Then multiple tissue microarrays were made from the paraffin-embedded sections.

\section{Immunohistochemistry and judgment of results}

The paraffin-embedded tissue microarrays sections were baked in the oven at $65^{\circ} \mathrm{C}$ for $12 \mathrm{~h}$. After deparaffinization and blocking, the antigen-antibody reaction was incubated overnight at $4^{\circ} \mathrm{C}$. The primary anti-Sufu rabbit monoclonal antibody (Cat No: ab52913,

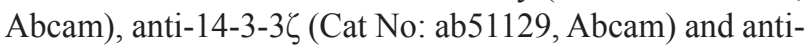
FoxM1(C-20) (Cat No: sc-502, Santa Cruz Biotechnology) 
were all used at a dilution of 1:100. Two independent pathologists (Y.N.Q and D.M.H) who were blinded to the clinicopathological information and corresponding slides of patients evaluate the immunohistochemical staining of Sufu, 14-3-3 $\zeta$ and FoxM1. A semiquantitative scoring method was followed: based on the staining intensity $(0$, negative staining; 1 , weak staining; 2 , moderate staining; 3 , strong staining) and the proportion of immunopositive cells $(1,<25 \% ; 2,25-50 \% ; 3,50-75 \% ; 4, \geq 75 \%)$. The final score for Sufu, 14-3-3 $\zeta$ and FoxM1 expression was the production of the two above-mentioned scores, ranging from 0 to 12 . For the statistical analysis, a final staining index of $0-4$ represented negative expression, whereas a staining index of 5-12 represented positive expression.

\section{Protein turnover assay}

To measure turnover of endogenous protein, $\mathrm{SiHa}$ cell was transfected with control and 14-3-3 $\zeta$ siRNA, respectively. 48 hours later, the cells were treated with cycloheximide (CHX, 20um, Sigma) to block protein synthesis. At the end of each time point, the cells were lysed in RIPA buffer (50 mM Tris- $\mathrm{HCl}, \mathrm{pH} 7.5$, $150 \mathrm{mM} 475 \mathrm{M} \mathrm{NaCl}, 1 \%$ Nonidet P-40, 0.5\% sodium deoxycholate, $0.1 \%$ SDS, 1xRoche complete Protease Inhibitor Cocktail))for western analysis.

\section{Chromatin immunoprecipitation (ChIP) assay}

ChIP was carried out as described previously [10]. Chromatin was cross-linked with $1 \%$ formaldehyde. Cells were incubated in ChIP lysis buffer $(150 \mathrm{mM} \mathrm{NaCl}, 25$ $\mathrm{mM}$ Tris $\mathrm{pH} 7.5,1 \%$ Triton $\mathrm{X}-100,0.1 \%$ SDS, $0.5 \%$ deoxycholate, 1xRoche complete Protease Inhibitor Cocktail). The reaction was stopped by the addition of $125 \mathrm{mM}$ glycine. DNA was fragmented into $200 \mathrm{bp}-$ $\sim 500$ bp pieces using a Sonics VCX130 sonicator. Aliquots of lysates containing $400 \mu \mathrm{g}$ of protein were used for each immunoprecipitation reaction with antiFoxM1 (Cat No: sc-502, Santa Cruz Biotechnology). Precipitated genomic DNA was amplified by PCR with primers as follows. Binding site (BS): Forward 5'-ATGAATCAATCCATTGTCAG-3'; Reverse 5'ACAGGCAGGGAAGGT- GT-3'.UP_5k: Forward 5'-AGCTGCTCCTATCTTACACTATTC-3', Reverse 5'CCCATTAAGTTCACAGCCTTTC-3'.

\section{Immunoprecipitation}

SiHa cells or transfected HEK293T were lysed in IP buffer (50 mM Tris- $\mathrm{HCl}, \mathrm{pH} 7.5,150 \mathrm{mM} \mathrm{NaCl}$, 1\%TritonX-100, 1xRoche complete Protease Inhibitor Cocktail), and the lysates were clarified by centrifugation for $15 \mathrm{~min}$ at $14,000 \mathrm{xg}$. The protein concentration of each cell lysate sample was determined by BCA assay. Immunoprecipitation was carried out with anti-FoxM1 (Cat No: sc-502, Santa Cruz) or anti-GFP (Cat No: MA5-
15256, Thermo Fisher), coupled to Protein G agarose beads (Millipore, USA) and the isolated proteins were subjected to $8 \%$ SDS-PAGE, and followed by Western analysis.

\section{Immunofluorescence}

Approximately $1 \times 10^{5}$ cells were seeded in one well of a Lab-TEK chambered slide. For each siRNA transfected described, 48h later, cells were harvested and washed with PBS, fixed with 4\% PFA at $4{ }^{\circ} \mathrm{C}$ for 10 minutes, then washed with PBS again. Immunofluorescence staining of EMT markers with following antibodies: anti-Vimentin (Cat No: 10366-1-AP, Proteintech) and anti-E-cadherin (Cat No: 610181, BD, Biosciences). Fluorescence was visualized with Olympus X71.

\section{RNA isolation, $R T$ and real-time PCR}

RNA isolation was carried out as described previously [35]. Total RNAs were isolated from cultured cells using the RNAiso reagent (TaKaRa, Shiga, Japan), and reverse transcription reaction was carried out using the PrimeScript RT reagent Kit (TaKaRa).Real-time PCR was carried out using the FastStart SYBR Green Master mix (Roche) on a 7500 Real-Time PCR System (Applied Biosystems) with primers for: RT-hPtch1-F':GCTGCACTACTTCAGAGACTGG, RT-hPtch1-R': CACCAGGAGTTTGTAGGCAAGG. RThSufu-F': CAGCAAACCTGTCCTTCCACCA, RT-hSufu-R': CAGATGTACGCTCTCAAGCTGC.RT-hGli1-F': AGCCTT CAGCAATGCCAGTG- AC, RT-hGli1-R':GTCAGGACC ATGCACTGTCTTG.RT-hFoxM1-F': GGAGCAGCGAC AGGT- TAAGG, RT-hFoxM1-R':GTTGATGGCGAA TTGTATCATGG.RT-hActin-F': ACCTTCTACAA- TGAG CTGCG, RT-hActin-R':CCTGGATAGCAACGTACATGG. RT-h14-3-3ל-F':CTACCGTTA- CTTGGCTGAGG, RTh14-3-3ל-R': CCAGTCTGATAGGATGTGTTGG. RThE-cadherin-F': CCCAATACATCTCCCTTCACAG, RT-hE-cadherin-R': CCACCTCTAAGGCCATCTTTG. RThVim-F':CGTGAATACCAAGACCTGCTC, RT-hVim-R': GGAAAAGTTTGGAAGAGGCA- G. Experiments were repeated at least three times, and samples were analyzed in triplicates.

\section{Cell migration and invasion assays}

Cell migration and invasion assays were carried out as described previously [36]. For assessing SiHa and HCC94 cell migration, $2 \times 10^{4}$ cells in serum free media were seeded into the transwell inserts (Corning) and allowed to migrate toward $10 \%$ FBS-containing medium. Later, the cells in the transwell inserts were removed, and the inserts were washed in PBS three times. The migrated cells on the bottom of the insert were fixed with methanol solution followed by crystal violet (1\%) staining. After washing the inserts three times with PBS, the inserts 
were allowed to air dry and pictures were taken using Olympus X71. Six independent fields were counted for each transwell and the average number of penetrating cells was represented in the graphs. For assessing cell invasion, $2 \times 10^{4}$ cells in serum-free medium were seeded in the matrigel-coated transwell inserts (BD Bioscience). The cells were later processed similar to that of cell migration assay.

\section{Luciferase reporter assay}

HEK297T Cells were transfected with the Sufu human promoter reporter plasmid together with pRL-TK and analyzed as described previously [10]. Luciferase activity was measured using a Dual-luciferase assay system (Promega, Madison, WI).

\section{Statistical analyses}

Statistical analyses were performed using SPSS 18.0 software. The results of IHC were analyzed with $\chi^{2}$ test and Spearman rank correlation test. All p-values were two-tailed, and p-values less than 0.05 were considered to indicate statistical significance.

\section{ACKNOWLEDGMENTS AND FUNDING}

We thank Steven Y. Cheng for Sufu construct. We wish to thank members of the Huang laboratory for technical assistance. This work was supported by grants from Jiangxi Province Youth Natural Science Foundation (no.20161BAB215261) to Z.Y.Z, the Social Development Foundation of Jiangxi Province (No. 20143ACG70016), the Chinese Natural Science Foundation (No. 81260097) to O.P.H and the Chinese National Natural Science Foundation (No. 81260384) to Y.Z.

\section{CONFLICTS OF INTEREST}

The authors declare no conflicts of interest.

\section{REFERENCES}

1. Anderson E, Peluso S, Lettice LA, Hill RE. Human limb abnormalities caused by disruption of hedgehog signaling. Trends Genet. 2012; 28:364-373.

2. Choudhry Z, Rikani AA, Choudhry AM, Tariq S, Zakaria F, Asghar MW, Sarfraz MK, Haider K, Shafiq AA, Mobassarah NJ. Sonic hedgehog signalling pathway: a complex network. Ann Neurosci. 2014; 21:28-31.

3. Jiang J, Hui CC. Hedgehog signaling in development and cancer. Dev Cell. 2008; 15:801-812.

4. McGlinn E, Tabin CJ. Mechanistic insight into how Shh patterns the vertebrate limb. Curr Opin Genet Dev. 2006; 16:426-432.
5. Ribes V, Briscoe J. Establishing and interpreting graded Sonic Hedgehog signaling during vertebrate neural tube patterning: the role of negative feedback. Cold Spring Harb Perspect Biol. 2009; 1:a002014.

6. Taylor MD, Liu L, Raffel C, Hui CC, Mainprize TG, Zhang X, Agatep R, Chiappa S, Gao L, Lowrance A, Hao A, Goldstein AM, Stavrou T, et al. Mutations in SUFU predispose to medulloblastoma. Nat Genet. 2002; 31:306-310.

7. Ding Q, Fukami S, Meng X, Nishizaki Y, Zhang X, Sasaki H, Dlugosz A, Nakafuku M, Hui C. Mouse suppressor of fused is a negative regulator of sonic Hedgehog signaling and alters the subcellular distribution of Gli1. Curr Biol. 1999; 9:1119-1122.

8. Kogerman P, Grimm T, Kogerman L, Krause D, Unden AB, Sandstedt B, Toftgard R, Zaphiropoulos PG. Mammalian suppressor-of-fused modulates nuclear-cytoplasmic shuttling of Gli-1. Nat Cell Biol. 1999; 1:312-319.

9. Cheng SY, Bishop JM. Suppressor of Fused represses Glimediated transcription by recruiting the SAP18-mSin3 corepressor complex. Proc Natl Acad Sci U S A. 2002; 99:5442-5447.

10. Zhang Z, Shen L, Law K, Zhang Z, Liu X, Hua H, Li S, Huang H, Yue S, Hui CC, Cheng SY. Suppressor of Fused chaperones Gli proteins to generate transcriptional responses to Sonic Hedgehog signaling. Mol Cell Biol. 2016.

11. Chen MH, Wilson CW, Li YJ, Law KK, Lu CS, Gacayan R, Zhang X, Hui CC, Chuang PT. Cilium-independent regulation of Gli protein function by Sufu in Hedgehog signaling is evolutionarily conserved. Genes Dev. 2009; 23:1910-1928.

12. Park KS, Martelotto LG, Peifer M, Sos ML, Karnezis AN, Mahjoub MR, Bernard K, Conklin JF, Szczepny A, Yuan J, Guo R, Ospina B, Falzon J, et al. A crucial requirement for Hedgehog signaling in small cell lung cancer. Nat Med. 2011; 17:1504-1508.

13. Chong Y, Tang D, Gao J, Jiang X, Xu C, Xiong Q, Huang Y, Wang J, Zhou H, Shi Y, Wang D. Galectin-1 induces invasion and the epithelial-mesenchymal transition in human gastric cancer cells via non-canonical activation of the Hedgehog signaling pathway. Oncotarget. 2016; 7:83611-83626. https://doi.org/10.18632/oncotarget.13201.

14. Kaye SB, Fehrenbacher L, Holloway R, Amit A, Karlan B, Slomovitz B, Sabbatini P, Fu L, Yauch RL, Chang I, Reddy JC. A phase II, randomized, placebo-controlled study of vismodegib as maintenance therapy in patients with ovarian cancer in second or third complete remission. Clin Cancer Res. 2012; 18:6509-6518.

15. Bohr Mordhorst L, Ahlin C, Sorbe B. Prognostic impact of the expression of Hedgehog proteins in cervical carcinoma FIGO stages I-IV treated with radiotherapy or chemoradiotherapy. Gynecol Oncol. 2014; 135:305-311. 
16. Xuan YH, Jung HS, Choi YL, Shin YK, Kim HJ, Kim KH, Kim WJ, Lee YJ, Kim SH. Enhanced expression of Hedgehog signaling molecules in squamous cell carcinoma of uterine cervix and its precursor lesions. Mod Pathol. 2006; 19:1139-1147.

17. Chakraborty C, Dutta S, Mukherjee N, Samadder S, Roychowdhury A, Roy A, Mondal RK, Basu P, Roychoudhury S, Panda CK. Inactivation of PTCH1 is associated with the development of cervical carcinoma: clinical and prognostic implication. Tumour Biol. 2015; 36:1143-1154.

18. Obsil T, Obsilova V. Structural basis of 14-3-3 protein functions. Semin Cell Dev Biol. 2011; 22:663-672.

19. Tzivion G, Shen YH, Zhu J. 14-3-3 proteins; bringing new definitions to scaffolding. Oncogene. 2001; 20:6331-6338.

20. Kim YH, Kim YS, Kang SS, Noh HS, Kim HJ, Cho GJ, Choi WS. Expression of 14-3-3 zeta and interaction with protein kinase $\mathrm{C}$ in the rat retina in early diabetes. Diabetologia. 2005; 48:1411-1415.

21. $\mathrm{Fu} \mathrm{H}$, Subramanian RR, Masters SC. 14-3-3 proteins: structure, function, and regulation. Annu Rev Pharmacol Toxicol. 2000; 40:617-647.

22. Gardino AK, Yaffe MB. 14-3-3 proteins as signaling integration points for cell cycle control and apoptosis. Semin Cell Dev Biol. 2011; 22:688-695.

23. Cerami E, Gao J, Dogrusoz U, Gross BE, Sumer SO, Aksoy BA, Jacobsen A, Byrne CJ, Heuer ML, Larsson E, Antipin Y, Reva B, Goldberg AP, et al. The cBio cancer genomics portal: an open platform for exploring multidimensional cancer genomics data. Cancer Discov. 2012; 2:401-404.

24. Gao J, Aksoy BA, Dogrusoz U, Dresdner G, Gross B, Sumer SO, Sun Y, Jacobsen A, Sinha R, Larsson E, Cerami E, Sander C, Schultz N. Integrative analysis of complex cancer genomics and clinical profiles using the cBioPortal. Sci Signal. 2013; 6:pl1.

25. Madeira F, Tinti M, Murugesan G, Berrett E, Stafford M, Toth R, Cole C, MacKintosh C, Barton GJ. 14-33-Pred: improved methods to predict 14-3-3-binding phosphopeptides. Bioinformatics. 2015; 31:2276-2283.

26. Chen Y, Yue S, Xie L, Pu XH, Jin T, Cheng SY. Dual phosphorylation of suppressor of fused (Sufu) by PKA and GSK3beta regulates its stability and localization in the primary cilium. J Biol Chem. 2011; 286:13502-13511.
27. Bergamaschi A, Christensen BL, Katzenellenbogen BS. Reversal of endocrine resistance in breast cancer: interrelationships among 14-3-3zeta, FOXM1, and a gene signature associated with mitosis. Breast Cancer Res. 2011; 13:R70.

28. Chan DW, Yu SY, Chiu PM, Yao KM, Liu VW, Cheung AN, Ngan HY. Over-expression of FOXM1 transcription factor is associated with cervical cancer progression and pathogenesis. J Pathol. 2008; 215:245-252.

29. Korver W, Roose J, Clevers H. The winged-helix transcription factor Trident is expressed in cycling cells. Nucleic Acids Res. 1997; 25:1715-1719.

30. Xu J, Acharya S, Sahin O, Zhang Q, Saito Y, Yao J, Wang H, Li P, Zhang L, Lowery FJ, Kuo WL, Xiao Y, Ensor J, et al. 14-3-3zeta turns TGF-beta's function from tumor suppressor to metastasis promoter in breast cancer by contextual changes of Smad partners from p53 to Gli2. Cancer Cell. 2015; 27:177-192.

31. Hanahan D, Weinberg RA. Hallmarks of cancer: the next generation. Cell. 2011; 144:646-674.

32. Chen H, Wang J, Yang H, Chen D, Li P. Association between FOXM1 and hedgehog signaling pathway in human cervical carcinoma by tissue microarray analysis. Oncol Lett. 2016; 12:2664-2673.

33. Karunarathna U, Kongsema M, Zona S, Gong C, Cabrera E, Gomes AR, Man EP, Khongkow P, Tsang JW, Khoo US, Medema RH, Freire R, Lam EW. OTUB1 inhibits the ubiquitination and degradation of FOXM1 in breast cancer and epirubicin resistance. Oncogene. 2016; 35:1433-1444.

34. Wang Y, Zhou X, Xu M, Weng W, Zhang Q, Yang Y, Wei P, Du X. OTUB1-catalyzed deubiquitination of FOXM1 facilitates tumor progression and predicts a poor prognosis in ovarian cancer. Oncotarget. 2016; 7:36681-36697. https:// doi.org/10.18632/oncotarget.9160.

35. Yue S, Tang LY, Tang Y, Tang Y, Shen QH, Ding J, Chen Y, Zhang Z, Yu TT, Zhang YE, Cheng SY. Requirement of Smurf-mediated endocytosis of Patched1 in sonic hedgehog signal reception. Elife. 2014.

36. Avasarala S, Van Scoyk M, Karuppusamy Rathinam MK, Zerayesus S, Zhao X, Zhang W, Pergande MR, Borgia JA, DeGregori J, Port JD, Winn RA, Bikkavilli RK. PRMT1 is a novel regulator of epithelial-mesenchymaltransition in non-small cell lung cancer. J Biol Chem. 2015; 290:13479-13489. 